\title{
OS GRUPOS DE DANCA POPULAR DE OLINDA E RECIFE: LIMITES E FRONTEIRAS NO SÉCULO XXI ${ }^{1}$
}

\author{
Ana Carolina Marques da Silva \\ Universidade de Pernambuco, Recife, Pernambuco, Brasil. \\ Adriana de Faria Gehres \\ Universidade de Pernambuco, Recife, Pernambuco, Brasil.
}

\begin{abstract}
Resumo
O estudo objetivou compreender os sentidos e os significados de atuação dos grupos de dança popular situados em Recife e em Olinda e caracteriza-se por uma abordagem qualitativa do tipo fenomenológico, a partir de uma análise de conteúdo, através de entrevistas semiestruturadas presenciais com os responsáveis pelos grupos. Os resultados apontaram para várias camadas de atuação dos grupos. A transmissão da cultura local foi o sentido mais atribuído pelos grupos quando se prontificam a divulgar e a preservar a dança popular. A fronteira entre a atuação como motor/indutor/produtor da cultura popular reverbera e retorna como grupo cênico e teatral. O trânsito instalado propõe zonas de ebulição que ora multiplicam, ora subtraem sua potência como ética, estética, arte e política.
\end{abstract}

Palavras-chave: Dança. Área de atuação profissional. Cultura.

\section{THE POPULAR DANCING GROUPS OF OLINDA AND RECIFE: LIMITS AND BORDERS IN THE XXI CENTURY}

\begin{abstract}
The study aimed at the meanings of the acting of the Popular Dance Groups located in Recife and Olinda and is characterized by a qualitative approach of the phenomenological type based on a content analysis, through semi-structured interviews with those responsible for the groups. The results pointed to several layers of performance of the groups. The transmission of the local culture was the sense most attributed by the groups when they are ready to spread and preserve the popular dance. The boundary between acting as an engine / inductor / producer of popular culture reverberates and returns as a stage and theatrical group. The installed traffic proposes zones of boiling that sometimes multiplies, sometimes subtracting its power as ethics, aesthetics, art and politics.
\end{abstract}

Keywords: Dancing. Professional Practice Location. Culture.

\section{LOS GRUPOS DE DANZA POPULAR DE OLINDA Y RECIFE: LÍMITES Y FRONTERAS EN EL SIGLO XXI}

\begin{abstract}
Resumen
El estudio tuvo el objetivo de comprender los sentidos y significados de actuación de los Grupos de Danza Popular situados en Recife y Olinda y se caracteriza por un enfoque cualitativo del tipo fenomenológico a partir de un análisis de contenido, a través de entrevistas semiestructuradas presenciales con los responsables por los grupos. Los resultados indicaron varios
\end{abstract}


segmentos de actuación de los grupos. La transmisión de la cultura local fue el sentido más atribuido por los grupos cuando se disponen a divulgar y preservar la danza popular. La frontera entre una actuación como motor/inductor/productor de la cultura popular repercute y retorna como grupo escénico y teatral. El tránsito instalado propone zonas de ebullición que ora multiplica, ora sustrae su potencia como ética, estética, arte y política.

Palabras clave: Danza. Área de la Práctica profesional. Cultura.

\section{Introdução}

O Perfil dos Municípios Brasileiros, apresentado através da Pesquisa de Informações Básicas Municipais (MUNIC), revela que, na última década, a dança sempre esteve entre as quatro atividades artísticas mais exercidas no país, destacando-se nas regiões Sul e Nordeste (IBGE, 2006, 2012, 2014).

Quando observada social e historicamente, a dança carrega diversos sentidos e significados nas suas formas sociais, individuais e coletivas, independentemente de o objetivo ser de lazer, de desenvolvimento de habilidades e capacidades, religioso, de representação cultural ou artística, apresentadas em suas múltiplas formas, como: danças sagradas, danças teatrais, danças populares ou tradicionais, etc. (CAMINADA, 1999).

Os grupos de dança popular são compreendidos neste trabalho como um segmento que se desenvolve nas fronteiras (HANNERZ, 1997) entre as danças teatrais e as danças populares ou tradicionais, organizados como grupos profissionais e amadores que produzem espetáculos de dança. Tendo como base folguedos e danças tradicionais do Nordeste brasileiro, destacamse pela grande persistência e pela quantidade em Pernambuco (OLIVEIRA, 1993).

Especificamente em Pernambuco, os grupos de dança popular desenvolveram-se a partir de uma iniciativa denominada "Movimento de Cultura Popular (MCP)", ao final da década de 1950, a qual tinha um caráter político, de iniciativa do então prefeito Miguel Arraes, em prol da luta pela superação do déficit escolar básico, na perspectiva de uma educação política baseada na valorização do conhecimento popular e na democratização da arte, da saúde e do lazer (GEHRES, 1994).

Desde a época e após enfrentar cenários políticos desafiadores, bem como a repressão durante a ditadura militar a movimentos populares, a dança popular vem ganhando espaços e sendo difundida por diversos grupos de dança popular, com diferentes formas de organização e atuação (GEHRES, 1994).

No início da década de 1970, pôde-se observar uma reviravolta no cenário da cultura e principalmente da dança popular, ao se instituir um novo movimento, por iniciativa de Ariano Suassuna, denominado de Movimento Armorial (GEHRES, 1994). "A ideia central do Movimento Armorial, era que a emancipação política, econômica, social e cultural do Brasil, se faria por meio da valorização da arte e do artista popular" (GALDINO, 2010, p. 16).

A partir do Movimento Armorial surge o Balé Armorial, conjugando técnicas eruditas com manifestações populares e construindo uma dança no diálogo entre as manifestações populares e a dança clássica (GALDINO, 2010; MARQUES, 2008).

O movimento deu origem ao Balé Popular do Recife (BPR), que, apesar de não concordar com a aproximação da "cultura erudita" da dança, intenção inicial do Movimento Armorial, estabeleceu-se como um grupo de dança popular, grupos que se baseavam em elementos da cultura popular para a criação de espetáculos cênicos (OLIVEIRA, 1993).

Galdino (2010) evidencia que a ampliação do cenário da dança popular no Recife desde os anos 70 do século passado conecta-se diretamente com a atuação do BPR. Apesar da inexistência de estudos que mensurem a quantidade de grupos, professores e bailarinos da 
dança popular que surgiram a partir dele, a autora destaca o BPR como o principal disseminador da dança popular, influenciando gerações de dançarinos e coreógrafos.

A ampliação desses grupos nas últimas décadas, bem como a permanência dos grupos mais antigos originados ou não a partir do BPR (VICENTE; SOUZA, 2012), deve ser abordada, investigada e compreendida a partir de diferentes ângulos e construtos teóricos (SILVA, 2011).

Vicente (2008) cita que uma das grandes dificuldades de se abordar a dança popular e seus grupos como teoria discursiva ou investigação científica está associada à incompletude de qualquer tipo de registro existente sobre eles.

Assim, na ausência de estudos detalhados e em profundidade sobre esses grupos de dança popular que se estabeleceram no período posterior aos anos 70, empreendemos este estudo com o objetivo de compreender os sentidos e os significados que se constituem para/na atuação dos grupos de dança popular situados em Recife e em Olinda - PE, bem como descrever as suas formas de organização, atuação e funcionamento.

\section{Metodologia}

O estudo caracteriza-se como uma pesquisa qualitativa, de base fenomenológica, que procura identificar "[...] em que sentidos há sentidos" (REZENDE, 1990, p. 17). A finalidade desse tipo de pesquisa se concentra na descoberta de caminhos coerentes e lógicos que nos permitam chegar a uma solução para o problema da pesquisa por meio de análises semânticas ou de conteúdos dos textos (THOMAS; NELSON, 2002).

\section{População e amostra}

Considerando o universo investigado (grupos/companhias de dança popular das cidades de Recife e Olinda), os grupos foram selecionados através de uma amostragem não probabilística intencional. O critério para inclusão no estudo foi a representatividade do trabalho realizado em dança nos últimos cinco anos nas cidades de Recife e Olinda. A representatividade foi estabelecida pela participação em ao menos dois referenciais da dança cênica no estado, a saber: Acervo Recordança, Funcultura e festivais e mostras das duas cidades (Festival Internacional de Dança, Festival Pernambuco em Dança e Mostra Brasileira de Dança). Foram identificados seis grupos. Para a coleta dos dados, foi realizada uma entrevista semiestruturada com um gestor/gestora de cada grupo. Abaixo segue a caracterização deles.

GRUPO 1: Grupo de dança popular e ponto de cultura com foco na dança afro, afroprimitiva e afro-brasileira, fundado em novembro de 1985. GESTORA 1: Co-diretora.

GRUPO 2: Grupo de dança popular com escola de dança própria, fundado em 1977. GESTORA 2: Diretora.

GRUPO 3: Grupo de dança popular com escola de dança própria, fundado em agosto de 1999. GESTORA 3: Diretora e coreógrafa.

GRUPO 4: Grupo de dança popular e ponto de cultura, fundado em 198-. ${ }^{1}$ GESTOR 4: Professor e coreógrafo. coreógrafo.

GRUPO 5: Grupo de dança popular, fundado em 1980. GESTOR 5: Diretor e

\footnotetext{
${ }^{1} \mathrm{O}$ grupo 4 não nos forneceu o ano de fundação, tampouco encontramos em quaisquer veículo de informação.
} 
GRUPO 6: Grupo de dança e escola de dança popular com foco em dança afro e intervenções culturais, fundada em 1997. GESTORA 6: Coordenadora.

\section{Procedimentos de coleta de dados}

Após a identificação da amostra, realizamos a inquirição dos sujeitos responsáveis pela gestão dos grupos, seus diretores e/ou coordenadores. A inquirição se estabeleceu através da utilização de entrevistas semiestruturadas presenciais, respondidas oralmente, gravadas em suporte de áudio e transcritas contendo respeitosamente as informações concedidas pelos sujeitos. Posteriormente, as transcrições das entrevistas foram enviadas a eles para verificação da fidedignidade do conteúdo, permitindo-nos, após aprovação, o prosseguimento da pesquisa.

\section{Procedimentos de análise dos dados}

Inicialmente, os dados foram apresentados sob a forma de categorias analíticas, categorias empíricas e indicadores para organização e análise das informações. As categorias foram identificadas através de análise de conteúdo, que consiste na organização das informações, sem haver desvios do material analisado por indução, mas que permite revelar "índices invisíveis ao nível dos dados brutos" (BARDIN, 2004, p. 117).

As categorias foram surgindo a partir de recorrentes leituras das transcrições das entrevistas, considerando sempre o objetivo do estudo, a fim de identificarmos as respostas para a lacuna proposta. Ao mesmo tempo, abrimos espaço para eventuais questões que pudessem surgir a partir das falas dos sujeitos.

O processo de análise das entrevistas recolhidas foi concluído a partir da sistematização e da organização das unidades de registro distribuídas de modo flexível em categorias que foram ajustadas até que se verificassem a objetividade, a produtividade e a fidelidade ao estudo (BARDIN, 2004). Em suma, a análise dos dados das entrevistas consistiu na procura de um discurso singular a partir dos discursos de cada um dos entrevistados.

O quadro abaixo descreve as categorias analíticas e empíricas identificadas nas entrevistas:

\begin{tabular}{|c|l|}
\hline CATEGORIA (Analítica) & \multicolumn{1}{c|}{ CATEGORIA (Empírica) } \\
\hline \multirow{2}{*}{ ORIGEM } & Família \\
\cline { 2 - 2 } & Agrupamento anterior \\
\cline { 2 - 2 } & Educação \\
\cline { 2 - 2 } ORGANIZAÇÃo & Profissão \\
\hline \multirow{2}{*}{ OBJETIVOS (sentidos) } & Seleção para entrada \\
\cline { 2 - 2 } & Seleção interna \\
\cline { 2 - 2 } & Financiamento \\
\cline { 2 - 2 } & Gestão \\
\hline & Individuais \\
\cline { 2 - 2 } & Acesso à arte \\
\cline { 2 - 2 } & Transmissão da cultura popular \\
\cline { 2 - 2 } & Profissionalização \\
\hline
\end{tabular}

Tabela 2. Categorias analíticas e empíricas

Fonte: Elaborada pelos autores, 2017. 
Os procedimentos adotados nesta pesquisa estão de acordo com o código de ética para pesquisas mediante a submissão ao Comitê de Ética da Universidade de Pernambuco (CAAE: 36633414.8.0000.5192) e da assinatura do Termo de Consentimento Livre e Esclarecido (TCLE).

\section{Apresentação e discussão dos resultados}

Os resultados apresentados a seguir seguem a ordem de análise dos conteúdos anteriormente descritos, de acordo com as categorias analíticas e empíricas encontradas. (Tabela 2). Sendo assim, serão descritos os achados sobre a origem dos grupos e as suas formas de financiamento, gerenciamento e seleção, seguidos da análise dos significados atribuídos aos grupos de dança à sua prática e da interpretação dos sentidos encontrados nos discursos.

\section{Origem}

No que se refere à origem e à formação dos grupos, o primeiro destaque se estabelece quando identificamos que quatro destes originaram-se e consolidaram-se sob um eixo familiar. Esses quatro grupos também se constituíram a partir de um agrupamento anterior: um grupo de capoeira para o Grupo 1 e o Grupo 4; jogos e brincadeiras de rua para o Grupo 6; um agrupamento de shows infantis, no caso do Grupo 2.

Por outro lado, o Grupo 5, assim como o Grupo 4, surgem em torno de causas sociais relacionadas à educação, como a necessidade de manutenção das crianças e jovens no ambiente escolar e o déficit escolar básico presente na comunidade, sobretudo na educação infantil.

O surgimento dos grupos anteriormente analisados ocorre entre as décadas de 70 e 80 do século passado, com exceção do Grupo 6, fundado há apenas 15 anos, que apesar disto não se distancia das características de origem dos demais grupos. Sintetizando, a origem dos grupos se atribui a vários motivos que perpassam por iniciativas de ação social e educacional quando tratados como um veículo para reforço social e escolar; relações com atividades artísticas e culturais anteriores até que se expandissem para grupos de dança propriamente ditos. Mas também identificamos o exercício da dança como profissão, como é o caso do Grupo 2, que surge também como uma iniciativa governamental.

Atualmente, a profissionalização, como fator de criação dos grupos, expande-se para outros grupos. O Grupo 3 surge por uma necessidade individual da coreógrafa em desenvolver sua metodologia de ensino da dança com um grupo próprio, com vistas à profissionalização não somente no campo da produção artística, mas também da formação.

Nesse contexto, o Grupo 2 e o Grupo 3 caracterizam-se como escolas de dança com o intuito de propagar a arte e captar recursos ao mesmo tempo, o que também pode ser identificado na origem do Grupo 4, o qual, antes de se tornar uma organização não governamental e posteriormente ponto de cultura, procurou se instituir como escola de dança.

A análise da origem dos grupos de dança em estudo condiz com a perspectiva de Vicente e Costa (2014), quando indicam que a história desses grupos parece apontar que suas realidades são heterogêneas entre si, distanciando-se e aproximando-se em alguns pontos.

Apesar de considerarmos que essas diferentes trajetórias podem ditar especificidades dos grupos no que diz respeito a sua criação, identificamos possíveis tensões entre os interesses pessoais que constituem sua origem, como as questões familiares e o interesse na dança e na cultura popular, versus a necessidade de institucionalização proveniente, em sua maioria, de respostas a ações de políticas culturais, que propõem formas e modos de 
funcionamento para requerer reconhecimento e financiamento. $\mathrm{Na}$ origem dos grupos em estudo, destacamos como ação política a iniciativa de criação do Balé Armorial, com Ariano Suassuna (GALDINO, 2010; MARQUES, 2008).

Identificamos, também, o aprofundamento das políticas culturais que adquiriram novos perfis com os governos implantados a partir de 2003. Destacamos a institucionalização de ações políticas como as do Ministério da Cultura (MINC), Programa Cultura Viva, dando origem aos pontos de cultura. No contexto local - Pernambuco -, salientamos as iniciativas da Secretaria de Cultura de Pernambuco (SECULT) e seu órgão executor, a Fundação do Patrimônio Histórico e Artístico de Pernambuco (FUNDARPE), incentivando grupos culturais, como os de dança popular, através de editais do Fundo Pernambucano de Incentivo à Cultura (FUNCULTURA) (ver FUNDARPE, 2013). ${ }^{2}$

Essas iniciativas instalam-se e tensionam com os modos mais tradicionais de fazer e existir, observadas nas formas de organização e financiamento dos grupos analisados a seguir.

\section{Organização}

Para identificação de como se organizam os grupos de dança popular atualmente, consideramos como categorias empíricas o processo de seleção dos bailarinos, as formas de financiamento do grupo e como se estabelece a gestão deles. Como consequência, identificamos várias regularidades nessas formas de organização e funcionamento.

Primeiramente, identificamos como sendo distintas as atividades de seleção para entrada no grupo daquelas que se estabelecem internamente, de acordo com demandas específicas. Consideramos, portanto, a seleção para entrada como sendo o processo em que são avaliados bailarinos para iniciar a participação nas atividades do grupo e as seleções internas como o processo de entrada dos bailarinos em eventos e espetáculos específicos, de acordo com a demanda, para atividades em/no curto prazo.

De acordo com as entrevistas, identificamos três indicadores para a seleção de entrada dos bailarinos nos grupos/companhias de dança popular. Predominantemente, a seleção dos grupos acontece a partir do convite a amigos e conhecidos, ou a entrada é aberta ao público interessado. Um terceiro indicador que apareceu em apenas uma situação foi o de níveis $e$ estágios.

No primeiro caso, os convites são feitos a amigos ou conhecidos que são indicados a participar do grupo, como exemplo do Grupo 5, Grupo 3 e do Grupo 1, como observamos no discurso:

Geralmente, um convida o outro, assim a gente sempre coloca que cada um pode ser um padrinho de mais um, então eles convidam amigos que queiram participar e a gente conversa com essas pessoas. (Feminino, co-diretora, Gestora 1).

No segundo caso, a entrada aberta nos grupos acontece naqueles que estão diretamente voltados para a prestação de serviços de formação e produção artística à comunidade (Grupo 4 e Grupo 6).

Um terceiro caso é identificado no processo de entrada no Grupo 2. É realizada uma seleção por estágios de atuação, nos quais o bailarino precisa ter uma experiência na própria escola de dança que lhe dê base para atuar no Grupo 2, considerado o último grau de atuação dos bailarinos da escola.

\footnotetext{
${ }^{2}$ Para saber mais:<http://www.cultura.pe.gov.br/funcultura/>. Acesso em: 08 fev. 2019.
} 
Portanto, com exceção do Grupo 2, atualmente os bailarinos são selecionados a partir do convite a amigos e conhecidos que já atuam com a dança ou, na ausência do convite, há a abertura para a comunidade para os interessados em participar.

Aqui, podemos observar que a seleção para entrada nos grupos caracteriza as fronteiras estabelecidas entre as formas de organização mais intimistas e locais, características das formações tradicionais e populares, e o processo de institucionalização gerado mediante a existência como grupo de apresentação cênica. Quando, por exemplo, há seleção de bailarinos por quesitos técnicos pela necessidade de aprimoramento cênico para apresentações específicas, em detrimento da necessidade de abertura do espaço para a entrada de pessoas que precisam do acesso à arte por conta de suas carências sociais e educacionais. No caso específico dos grupos estudados, três dos grupos atuam também como projetos sociais em dança.

As seleções internas foram identificadas em três dos grupos entrevistados, ocorrendo quando é preciso definir um elenco para uma determinada apresentação.

Os bailarinos selecionados podem ser escolhidos por qualificação, como acontece no Grupo 5, no qual há a separação entre novos e antigos, quando o "novato" não consegue se incluir no grupo, ou por demanda para determinada apresentação, como exemplo, no Grupo 2:

\footnotetext{
Quando é data de aniversário do balé, 15 anos, 20 anos, 25 anos. [...] É... porque às vezes a gente tá com 20 bailarinos, mas vai precisar de 50, então, precisamos de 30 pra entrar dentro desse espetáculo. Quer dizer que ele vai ficar dentro do espetáculo para a apresentação. (Feminino, diretora, Gestora 2).
}

Essas seleções, considerando que foram descritas por metade dos grupos analisados, podem ou não estar presentes nos outros grupos, a depender da quantidade de integrantes, da avaliação qualitativa dos bailarinos e da demanda de apresentações deles. Apesar da possibilidade, podemos considerar que essas características estão presentes e se aproximam mais dos grupos cênicos e com vínculos profissionais em detrimento daqueles que têm origens tradicionais, familiares etc., mais uma expressão da necessidade de adentrar um mercado profissional cênico.

Identificamos várias formas de financiamento para os grupos de dança popular, a saber: cachê (por apresentação, espetáculo, participação em eventos, entre outros), doação e parcerias, trocas de serviço, aulas, bilheterias, vendas de artesanato e auxílio governamental, quando considerados os pontos de cultura.

Em destaque, o cachê é a forma de captação de recursos mais utilizada pelos grupos, visto que todos relataram utilizar-se desse meio para suporte financeiro.

Notamos que, nos grupos com um vínculo social estreito com a comunidade, o que implica uma abertura maior com relação à seleção de pessoas para a entrada no grupo, há doações e parcerias como forma de financiamento, especificamente nos Grupos 4, 5 e 6 . As doações dizem respeito à alimentação dos participantes, a espaços para ensaio e materiais para apresentações que podem vir de alguma empresa privada, de parcerias com escolas públicas e dos próprios componentes que gerem o grupo, em prol da sua manutenção.

Metade dos grupos analisados utiliza-se da venda de materiais e artesanato, muitas vezes feitos pelos próprios participantes.

Grupos que hoje atuam com foco na profissionalização da dança, o Grupo 3 e o Grupo 2, possuem rendas advindas também do valor apurado com a comercialização das aulas de dança oferecidas nas escolas de dança dos grupos. 
Além desses meios de financiamento, a captação de recursos também ocorre através de bilheterias de espetáculos, trocas de serviços e através de um suporte governamental para grupos que são pontos de cultura, como o Grupo 1 e o Grupo 4.

Em suma, o financiamento dos grupos se estabelece através de diferentes instrumentos. Grande parte não conta com nenhum tipo de suporte governamental e todos se utilizam de cachês para a sua manutenção. Apesar disto, nem todos o utilizam como principal meio de captação de recursos, assim como também todos eles possuem renda advinda de duas ou mais formas de financiamento.

Estes dados evidenciam o desejo e o papel desses grupos no processo de institucionalização da dança popular como dança cênica. Mais uma vez identificamos que esses grupos se criam, se desenvolvem e se consolidam em uma zona de fronteira entre os modos de fazer das iniciativas tradicionais e da cultura popular e os grupos de dança cênica.

A gestão dos grupos se estabelece com base em três perspectivas: familiar, institucionalização e voluntariado.

Evidenciamos que os grupos que se originaram e ganharam forma alicerçados sob eixo familiar permanecem sendo geridos por membros da família no que diz respeito a sua direção, coordenação e coreografia, como consta nos discursos dos membros do Grupo 1, Grupo 2, Grupo 5 e Grupo 6.

Os grupos que hoje se colocam como grupo/companhia de dança profissional tendem à institucionalização e à legalização no processo de gestão. Como exemplo, temos o Grupo 5, que se organiza como organização social, apresentando diretoria com presidente, vicepresidente, tesoureiro e conselho fiscal. Outro exemplo é o Grupo 3, que, por se tratar de uma escola de dança, organiza-se como empresa.

[...] nesse sentido, na parte administrativa tem um contador que me auxilia, tem um escritório de advocacia que faz toda essa parte que precisa mais, porque você tem que fazer contrato especial, a gente passou a ser uma escola, então por conta da escola a gente teve que colocar bailarinos que dão aulas aqui aí já tem uma renda pra eles. (Feminino, diretora e coreógrafa, Gestora $3)$.

Em se tratando de gestão através de um trabalho voluntário, destacamos os grupos cujos objetivos são de ordem social, que têm abertura no processo de entrada e seleção e não possuem recursos financeiros advindos do governo ou da própria instituição, com exceção de alguns trabalhos artesanais feitos para suprir as necessidades do grupo. Em suma, o trabalho voluntário ocorre quando os que compõem o grupo se sentem responsáveis pela causa exercida pelo coletivo, identificadas nos discursos dos sujeitos do Grupo 4 e do Grupo 6.

\section{Objetivos (sentidos e significados atribuídos à atuação dos grupos)}

Vários foram os objetivos identificados nos discursos dos entrevistados quando questionados sobre o que é o grupo, os motivos que os levam a manter o grupo e o sentido dos grupos para ele(a) e os participantes. Dos objetivos apontados para a atuação dos grupos, destacamos quatro: garantir acesso à arte; transmitir a cultura popular; profissionalizar a atuação do trabalhador da dança, e questões individuais que perpassam uma abordagem emocional na relação com o grupo e a dança.

Segundo Barreto (2004), sentimentos e sensações fazem parte dos sentidos e significados concedidos à prática da dança, e eles se incluem como motivação para a permanência dos grupos de dança popular em estudo. Esses indicadores fazem parte dos objetivos individuais que os levam a se manter em atuação, creditando, em discurso, valor 
emocional ao que realizam, quando os sujeitos 2, 3 e 6 destacam o amor, a raça e a esperança como motivos para a permanência do grupo.

Além destes, o sujeito 5 descreve sua permanência destacando e correlacionando essas emoções e esses sentimentos à trajetória familiar desenvolvida pelo grupo nas últimas décadas.

\footnotetext{
A manutenção dele se dá por acreditar que isso não vai acabar enquanto tiver a $* * * * * * *$ [filha] que nasceu aqui, com 24 anos, então ela chegou aqui na barriga da mãe dela, dançou na barriga e hoje ela tá assumindo um trabalho, e aí minha filha de 13 anos tá dançando.... (Masculino, diretor e coreógrafo, Gestor 5).
}

Entre os achados, podemos reforçar estudos anteriores (GALDINO, 2010) quanto ao Grupo 5, que hoje é um agrupamento de artistas e bailarinos da dança com objetivos profissionais, mas que, apesar disto, ainda mantém vínculo com a causa social comunitária, assim como o Grupo 1. Essas causas são facultadas ao sentido de possibilitar o acesso à arte a partir da atuação desses grupos, tanto por uma questão de compensação quanto de facilitação a esse acesso para a comunidade onde intervêm.

Percebemos que, originalmente, ainda existia grande influência por parte de movimentos político-educacionais que, de certa forma, davam suporte financeiro e institucional para os manterem ativos (GEHRES, 1994). Contudo, todos os grupos que se constituíram dentro desse contexto atualmente seguem caminhos distintos. O Grupo 4, que se instituiu como uma escola de educação infantil, nos últimos dois anos encerrou essa atividade por ausência de suporte financeiro. Hoje, o grupo se volta para a necessidade de ofertar atividades de arte para a população local.

Notamos que, como em suas origens, há regularidades e singularidades nos sentidos e significados atribuídos pelos sujeitos à atuação dos grupos. Contudo, nestes podemos destacar uma tendência maior para as regularidades, presentes na ideia de resistência e valorização da cultura local.

A transmissão da cultura popular foi observada no discurso de todos os sujeitos entrevistados no que diz respeito à divulgação e à preservação da dança popular e da cultura local. O interesse em transmitir o trabalho realizado é percebido nos grupos em estudo, mesmo que eles tenham origens e perspectivas de atuação diferentes.

$\mathrm{O}$ sujeito 1 considerou que o conhecimento adquirido em anos de prática deve ser transmitido para que outras pessoas possam ter a mesma oportunidade de vivências, por isso, como consta, o objetivo do grupo é

[...] de valorizar, preservar e divulgar a cultura afro, afro brasileira e popular dentro e fora de nosso país. (Feminino, co-diretora, Gestora $1)$.

Essa preocupação com a divulgação também é percebida no Grupo 2 e no Grupo 3, na medida em que a divulgação da cultura popular potencializa a profissionalização. O objetivo, portanto, perpassa tanto a divulgação para o público quanto a colaboração no crescimento e no conhecimento dos próprios bailarinos e artistas que o compõem, ambos dentro da perspectiva da valorização da cultura local por intermédio da dança.

Conforme descrito, o objetivo de metade dos entrevistados está no exercício da profissão, observado desde a sua origem com o Grupo 2 e o Grupo 3 ou reconfigurados no processo de consolidação, como identificado no Grupo 5, tanto na análise realizada no presente estudo quanto em estudos desenvolvidos anteriormente (GALDINO, 2010). 
Quando relacionados aos sentidos atribuídos pelos sujeitos, a profissionalização do trabalho realizado com a dança popular foi enfatizada a partir da necessidade de valorização do artista que se desenvolve neste âmbito e que tem grande dificuldade de reconhecimento e crescimento profissional. Salientamos que todos os grupos que enfatizam a profissionalização e a maioria dos demais não contam com suporte financeiro governamental direto e necessitam "caminhar com os próprios pés" para garantir a sua sobrevivência. Assim, a dificuldade de sobrevivência se instaura e a tentativa de permanência se torna cada vez mais difícil.

Podemos, assim, concluir que os sentidos e os significados atribuídos à atuação dos grupos de dança popular estudados, em sua maioria, constituem-se no reconhecimento da vasta cultura local e da necessidade de desempenhar um papel de sua transmissão.

Apesar da constatação da instalação de programas e projetos federais e estaduais, no campo das políticas culturais, nos últimos anos, para a valorização das culturas e dos fazeres populares, afrodescendentes e indígenas e da dança (BRASIL, 2014; FUNCULTURA, 2003), os grupos de dança popular seguem se identificando com o papel de guardiães da cultura local, num processo de sobrevivência cotidiana em face de outras formas culturais e artísticas vividas socialmente. Essa constatação pode indicar uma representação de cultura que remete à diferenciação esquemática de seus fazeres, ainda que sejamos e vivamos em sociedades complexas e globalizadas do século XXI, que se instalam no conflito e no processo contínuo de hibridização e embate entre culturas e poderes (CANCLINI, 1999).

Por outro lado, as formas de organização (seleção, gestão, financiamento), origem e objetivos relacionadas à profissionalização como grupo artístico, e à institucionalização pela afirmação da nossa diversidade sociocultural (os pontos de cultura) e o acesso à arte por parte das populações que a ela não têm acesso, revelam a situação fronteiriça dos grupos, culminando em ressignificações permeáveis e mutantes que se instalam neste contexto de século XXI.

Essa interpretação nos interessa no sentido de olhar para a situação paradoxal que se instala: profissionalizar a brincadeira popular, os agrupamentos familiares, as formas de seleção e organização dos grupos pode, nesse contexto, significar não um processo de engessamento do grupo, mas a sua possibilidade de continuar pulsando. Nesse sentido, compreendemos que esse processo é e deve se instalar como uma zona de fronteira, no sentido que lhe atribui Hannerz (1997):

\begin{abstract}
Em suma, os cenários das zonas intersticiais parecem cheios de vida, mas não completamente seguros. Se uma pessoa é capaz de sobreviver e até prosperar nelas, isso se deve a sua própria agilidade cultural, talvez mesmo agilidade física. [...] A liberdade da zona fronteiriça é explorada com mais criatividade por deslocamentos situacionais e combinações inovadoras, organizando os seus recursos de novas maneiras, fazendo experiências. Nas zonas fronteiriças, há espaço para a ação [agency] no manejo da cultura. (HANNERZ, 1997, p. 23-24).
\end{abstract}

\title{
Discussão
}

Compreendemos aqui, ao versar sobre os grupos de dança popular situados em Recife e em Olinda, que discutir sobre os sentidos e os significados da atuação desses grupos no século XXI torna-se pulsante se considerarmos as várias camadas existentes desde as suas origens até as suas atuais formas de organização (seleção, financiamento e gestão) e objetivos. Existem claras tensões quanto ao modo de se fazer esses grupos, provenientes da complexa rede de possibilidades de sobrevivência que os mantêm ativos, que vão desde concepções individuais (sentimentos, família...) e tradicionais (origem) à institucionalização deles, 
oriundas, por exemplo, de ações de ordem política que os financiam e ampliam suas chances de visibilidade e reconhecimento.

Há uma zona de fronteira observada desde o processo de seleção de bailarinos, que por vezes é livre pela necessidade de alcance para garantia ao acesso à arte e por vezes ocorre para atender à necessidade de construção cênica; nas formas de financiamento e gestão quando precisam se institucionalizar para garantia da manutenção do grupo; até o sentido do grupo que, apesar de se constituir no reconhecimento da ampla cultura local e da necessidade de desempenhar um papel de sua transmissão, instaura-se juntamente com seus outros objetivos, ademais, que se ressignificam, atendendo aos processos de poder que os institucionaliza para que, assim, seja possível fazer cultura.

\section{Referências}

ACIOLY, P. L. Estilo de vida e insatisfação referida quanto ao trabalho entre BARDIN, L. Análise de conteúdo. 3. ed. Lisboa: Edições 70. 2004.

BARRETO, D. Dança ...: ensino, sentidos e possibilidades na escola. Campinas, SP: Autores Associados, 2004.

BRASIL. Cultura Viva. 2014. O que é a política nacional de Cultura Viva - PNCV?. Disponível em: <http://www.cultura.gov.br/cultura-viva1>. Acesso em: 25 dez. 2017.

CAMINADA, E. História da dança: evolução cultural. Rio de janeiro: Sprint, 1999.

CANCLINI, N. G. Consumidores e cidadãos: conflitos multiculturais a globalização. Rio de Janeiro: UFRJ, 1999.

DOMINGUES, Petrônio. Cultura popular: as construções de um conceito na produção historiográfica. História, São Paulo. v. 30, n. 2, p. 401-419, ago./dez. 2011

FERREIRA, T. Danças Folclóricas e danças populares: Limites e possibilidades da cultura popular. In: CONGRESSO NACIONAL DE PESQUISADORES EM DANÇA, 3, 2014. Anais... Comitê Dança em Mediações Educacionais, 2014.

FUNCULTURA. Fundo Pernambucano de Incentivo à Cultura. 2003. Disponível em: <http://www.cultura.pe.gov.br/funcultura/>. Acesso em: 25 dez. 2017

GALDINO, C. Balé Deveras: o social e o artístico em contextos populares. In: ENCONTRO NACIONAL DE HISTÓRIA ORAL. TESTEMUNHOS: HISTÓRIA E POLÍTICA, 10. 2010. Anais... Universidade Federal de Pernambuco (UFPE); Centro de Filosofia e Ciências Humanas, 2010.

GEHRES, A. F. O mundo da dança, palco de muitas escolas: um estudo das representações do conhecimento popular em um projeto de educação popular. 1994. 205f. Dissertação (Mestrado em Educação) - Universidade Federal de Pernambuco, 1994.

HANNERZ, U. Fluxos, fronteiras, híbridos: palavras-chave da antropologia transnacional. MANA, Rio de Janeiro, v. 1, n. 3, p. 7-39, 1997. 
MARQUES, R. R. Deslocamentos armoriais: da afirmação épica do popular na "Nação Castanha" de Ariano Suassuna ao corpo-história do Grupo Grial (primeira parte). 2008. 182f. Tese (Doutorado) - Programa de Pós-Graduação em Letras, Universidade Federal de Pernambuco, Recife, 2008.

OLIVEIRA, M. G. R. Danças populares como espetáculo público no Recife, de 1979 a 1988. 1993. Dissertação (Mestrado em História) - Universidade Federal de Pernambuco, Recife, 1993.

IBGE - Instituto Brasileiro de Geografia e Estatística. Pesquisas de Informações Básicas Municipais. Brasília: Perfil dos Municípios Brasileiros MUNIC, Caderno de cultura, 2006. p. 8790.

IBGE - Instituto Brasileiro de Geografia e Estatística. Pesquisas de Informações Básicas Municipais. Brasília: Perfil dos Municípios Brasileiros MUNIC, Caderno de cultura, 2012. p. 99102.

IBGE - Instituto Brasileiro de Geografia e Estatística. Pesquisas de Informações Básicas Municipais. Brasília: Perfil dos Municípios Brasileiros MUNIC, Caderno de cultura, 2014. p. 22. REZENDE, A. M. Concepção fenomenológica da educação. São Paulo: Cortez, 1990.

SILVA, S. S. Habitus e práticas da dança: uma análise sociológica dos fatores que influenciam a prática da dança na cidade de Toledo - PR. 2011. 142f. Dissertação (Mestrado em Educação Física) - Departamento de Educação Física, Setor de Ciências Biológicas, Universidade Federal do Paraná, 2011.

THOMAS, J. R.; NELSON, J. K. Métodos de pesquisa em atividade física. 3. ed. Porto Alegre: ARTMED, 2002.

VICENTE, A. V. R. Entre a ponta do pé e o calcanhar: reflexões sobre o frevo na criação coreográfica do Recife, na década de 1990: cultura, subalternidade e produção artística. 2008. 194f. Dissertação (Mestrado em Artes Cênicas) - Programa de Pós-graduação em Artes Cênicas, Universidade Federal da Bahia, 2008.

.; SOUZA, G. G. Q. Indicações para o ensino do frevo a partir de suas exigências físicas. In: CONGRESSO NACIONAL DE PESQUISADORES EM DANÇA - ANDA, 2. 2012. Anais... Comitê Dança em Mediações Educacionais, 2012.

.; COSTA, L. G. Ação, emoção e educação: tradições populares no palco da dança de Recife. Recife: Associação Reviva/Acervo Recordança; Departamento de Artes Cênicas UFPB, 2014. Disponível em: http://recordanca.com.br/. Acesso em: 25 dez. 2017.

Recebido em: 25/12/2017

Revisado em: 07/07/2018

Aprovado em: 04/10/2018

Endereço para correspondência:

anninhaamarques@hotmail.com

Ana Carolina Marques da Silva

Avenida Agamenon Magalhães, S/N

Santo Amaro, 50100-010 Recife - PE, Brasil 